\title{
A Study on Core Structure of High Frequency Transformer to Improve Efficiency of Module-Integrated Converter
}

\author{
Jin-Hyung Yoo and Tae-Uk Jung* \\ Department of Electrical Engineering, Kyungnam University, Chang-won, Korea
}

(Received 7 April 2014, Received in final form 25 June 2014, Accepted 25 June 2014)

\begin{abstract}
Recently, module-integrated converter (MIC) research has shown interest in small-scale photovoltaic (PV) generation. The converter is capable of efficient power generation. In this system, the high frequency transformer should be made compact, and demonstrate high efficiency characteristics. This paper presents a core structure optimization procedure to improve the efficiency of a high frequency transformer of compact size. The converter circuit is considered in the finite element analysis (FEA) model, in order to obtain an accurate FEA result. The results are verified by the testing of prototypes.
\end{abstract}

Keywords : high frequency, transformer, module-integrated, converter

\section{Introduction}

Recently, module-integrated converter research has shown interest in small-scale photovoltaic generation systems. The converter is capable of more efficient output power control of each PV module, and offers installation convenience, compared with a centralized converter [1-4]. The MIC is attached to the backside of the PV module. Generally, the height of the MIC should be under $20 \mathrm{~mm}$, to be placed within the PV module package.

In the module-integrated converter, the largest and tallest component is the high frequency transformer. This is also the most important component to decide the power conversion efficiency of the system, because of the high operating frequency [4-7]. In order to reduce the size and to improve the efficiency of the MIC, the high frequency transformer should be made compact, and demonstrate high efficiency characteristics.

In general studies, transformer design is done by using the approximated sinusoidal or square waveform voltage and current, for the convenience of analysis. Therefore, accurate analysis considering the real operation characteristics of a converter circuit is difficult [8-10].

In this paper, a core structure optimization procedure is studied, to improve the efficiency of a high frequency

(C)The Korean Magnetics Society. All rights reserved.

*Corresponding author: Tel: +82-55-249-2628

Fax: +82-505-999-2161, e-mail: tujung@kyungnam.ac.kr transformer of compact size. This procedure is based on the relationship between the window area, and the effective cross-sectional area of the core. The minimum window area of the core is determined by the current density in the windings, and the effective cross-sectional area is decided by the flux density in the core.

In addition, the model of a high frequency transformer is proposed for more accurate analysis, by considering the converter circuit.

\section{Initial Design and Analysis}

\subsection{Required specifications of the transformer}

Due to the low input voltage from the PV module, a tapped-inductor boost converter is applied to operate at a higher step-up conversion ratio, compared with the flyback converter. Fig. 1 shows the switching operation

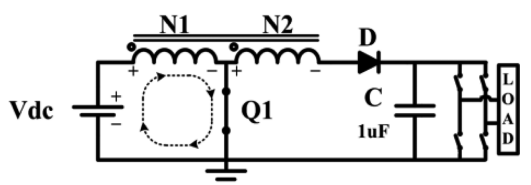

(a) $\mathrm{Q1}=$ On

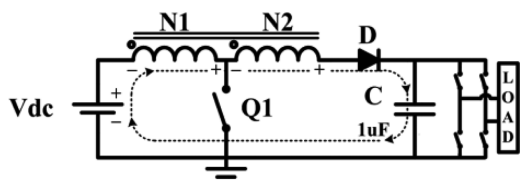

(b) $Q 1=$ Off

Fig. 1. Operational diagram of the converter. 
Table 1. Required Specifications of the transformer.

\begin{tabular}{lc}
\hline \multicolumn{1}{c}{ Parameter } & Value \\
\hline DC input voltage, $V_{\text {in }}[\mathrm{V}]$ & 30 \\
Rated output voltage $(\mathrm{rms})[\mathrm{V}]$ & 310 \\
Rated output power $(\mathrm{rms})[\mathrm{W}]$ & 120 \\
Rated operating frequency, $f_{o}[\mathrm{kHz}]$ & 100 \\
Turn ratio [N1:N2] & $1: 5$ \\
Inductance of Primary winding $[\mu \mathrm{H}]$ & 15 \\
Height [mm] & $\leq 15$ \\
Efficiency [\%] & $\geq 95$ \\
\hline
\end{tabular}

modes of the converter. The required specifications of the transformer are summarized in Table 1.

\subsection{Initial core structure design}

The initial core structure is based on an RM type core, which has the advantage that it can be highly integrated into the printed circuit board (PCB). In order to select the smallest standard core, the minimum window area $\left(W_{a}\right)$ and the effective cross-sectional area of the core $\left(A_{c}\right)$ are calculated.

The total conduction area of the winding $\left(A_{w}\right)$ is determined by the maximum current density $\left(J_{\max }\right)$, and the number of turns in each winding, from Eq. (1). Generally, the range of the maximum current density is $4-5 \mathrm{~A} / \mathrm{mm}^{2}$.

$$
A_{w}=N_{p}\left(\frac{I_{p \text { max }}}{J_{\max }}\right)+N_{s}\left(\frac{I_{s \max }}{J_{\max }}\right)
$$

The minimum window area is calculated from Eq. (2). The window area should consider the size of the insulator among the windings and the core, through the utilization factor $\left(k_{u}\right)$. The utilization factor of the window area depends on the voltage difference between the primary and secondary winding.

$$
\frac{A_{w}}{K_{u}}=W_{a}
$$

From Eq. (3), the maximum flux density of the core $\left(B_{\max }\right)$ is calculated by the maximum current $\left(I_{\max }\right)$, instead of the non-linear voltage waveform. The $B_{\max }$ should be lower than the saturation flux density of the core material $\left(B_{\text {sat }}\right)$, by sizing the $A_{c}$.

The selected smallest standard core structure and the B$\mathrm{H}$ curve of the core material are shown in Fig. 2.

$$
B_{\max }=\frac{I_{p} I_{\max } \times 10^{8}}{N_{p} \times A_{c}}
$$

\subsection{FEA modeling and analysis result}

In order to analyze the operating characteristics of the initial model, a FEA model is proposed, as shown in Fig. 3. The time step interval is given as the greatest common measure of the turn-on and turn-off time, to obtain the current waveform of each winding with high accuracy. The result of the analysis is compared with the measurement result of the initial model, to check the accuracy of the model. The analysis result is nearly similar to the measurement result, as shown in Fig. 4.

The results are displayed in Table 2. The portion of copper loss is very much larger than the core loss, because the inductance of the winding is less than required.

In addition, the core is partly saturated, as shown in Fig. 5. In order to improve the efficiency and to reduce the size of core, design improvement to minimize the copper loss should be made.

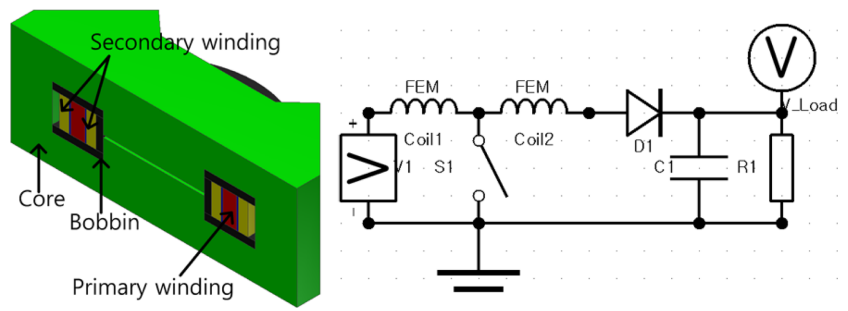

Fig. 3. (Color online) Analysis model of the transformer.

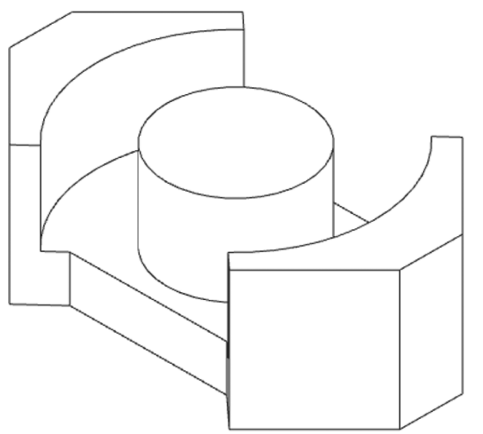

(a)

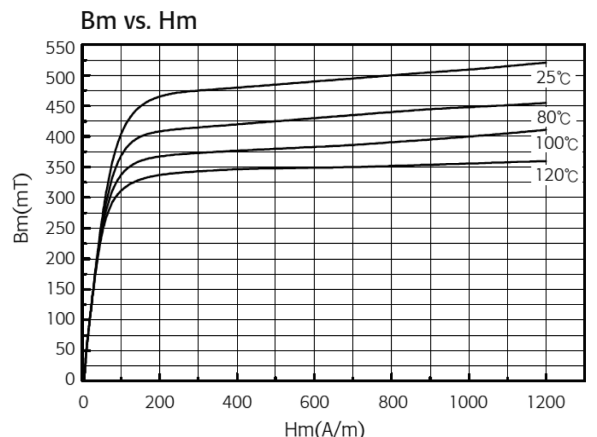

(b)

Fig. 2. (a) Half structure of the standard core, and (b) B-H curve of the core. 

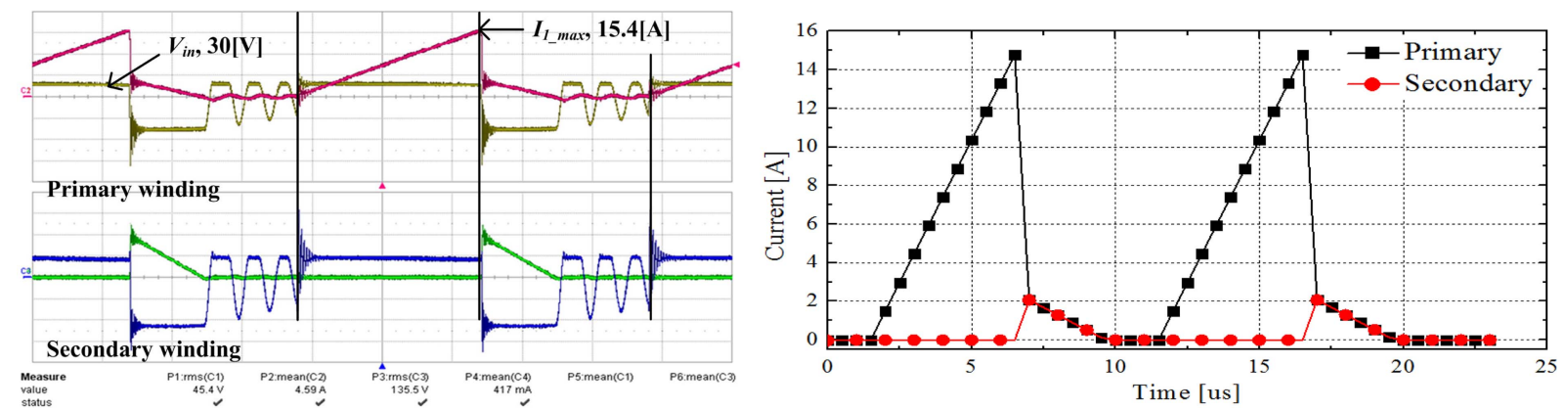

Fig. 4. (Color online) Comparison of the analysis and measurement results.

Table 2. Loss analysis result of the initial model.

\begin{tabular}{ccccccc}
\hline \hline Model & $\begin{array}{c}\mathrm{P}_{\text {in }} \\
{[\mathrm{W}]}\end{array}$ & $\begin{array}{c}\mathrm{P}_{\text {out }} \\
{[\mathrm{W}]}\end{array}$ & $\begin{array}{c}\mathrm{P}_{\text {core }} \\
{[\mathrm{W}]}\end{array}$ & $\begin{array}{c}\mathrm{P}_{\text {cu-1 }} \\
{[\mathrm{W}]}\end{array}$ & $\begin{array}{c}\mathrm{P}_{\text {cu-2 }} \\
{[\mathrm{W}]}\end{array}$ & $\begin{array}{c}\text { Efficiency } \\
{[\%]}\end{array}$ \\
\hline Initial & 135.2 & 120.8 & 3.08 & 6.5 & 4.6 & 89.4 \\
\hline
\end{tabular}

\section{Core Structure Optimization}

\subsection{Optimization procedure}

The loss characteristics between the core and the copper loss at different frequencies in the high frequency transformer are shown in Fig. 6. In this figure, (a) and (c) indicate the optimum flux density at each frequency, and (b) indicates the saturation flux density of the core material.

The total loss of the transformer $\left(\mathrm{P}_{\text {loss }}\right)$ is minimized, when the copper loss $\left(\mathrm{P}_{\mathrm{cu}}\right)$ is approximately equal to the core loss $\left(\mathrm{P}_{\text {core }}\right)$, regardless of the operating frequency [2].

In this study, the optimization procedure is based on the correlation characteristics between the core and copper loss, as shown in Fig. 7. In this procedure, the window area is the major factor for optimization, instead of the flux density.

Due to the reduced height of the core, the height of the window area should be less than the initial value, to pre-

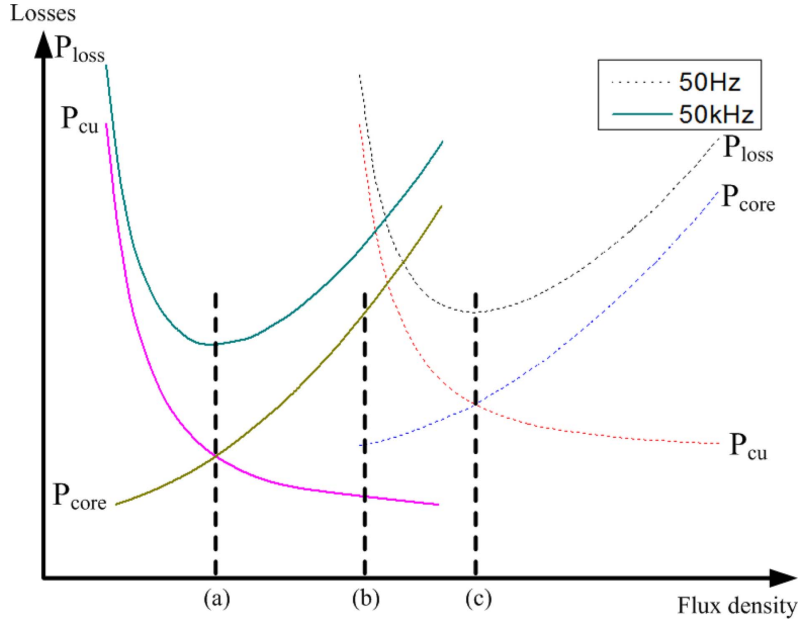

Fig. 6. (Color online) Core, copper and total losses at different frequencies.

vent saturation of the core.

An optimal inductance calculation step is added, to prevent saturation of the primary winding. The air-gap length of core is determined by the center leg area, and the optimal inductance of the primary winding. The component ratio of loss is analyzed by using the proposed analysis model.

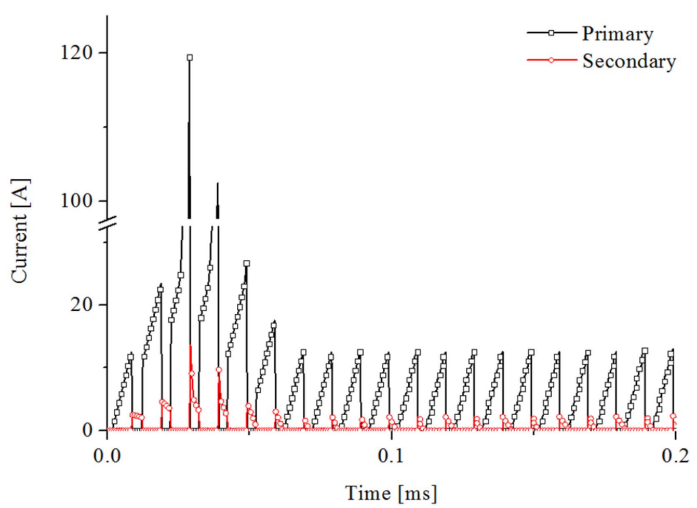

Fig. 5. (Color online) Flux density distribution and winding current waveform of the initial model. 

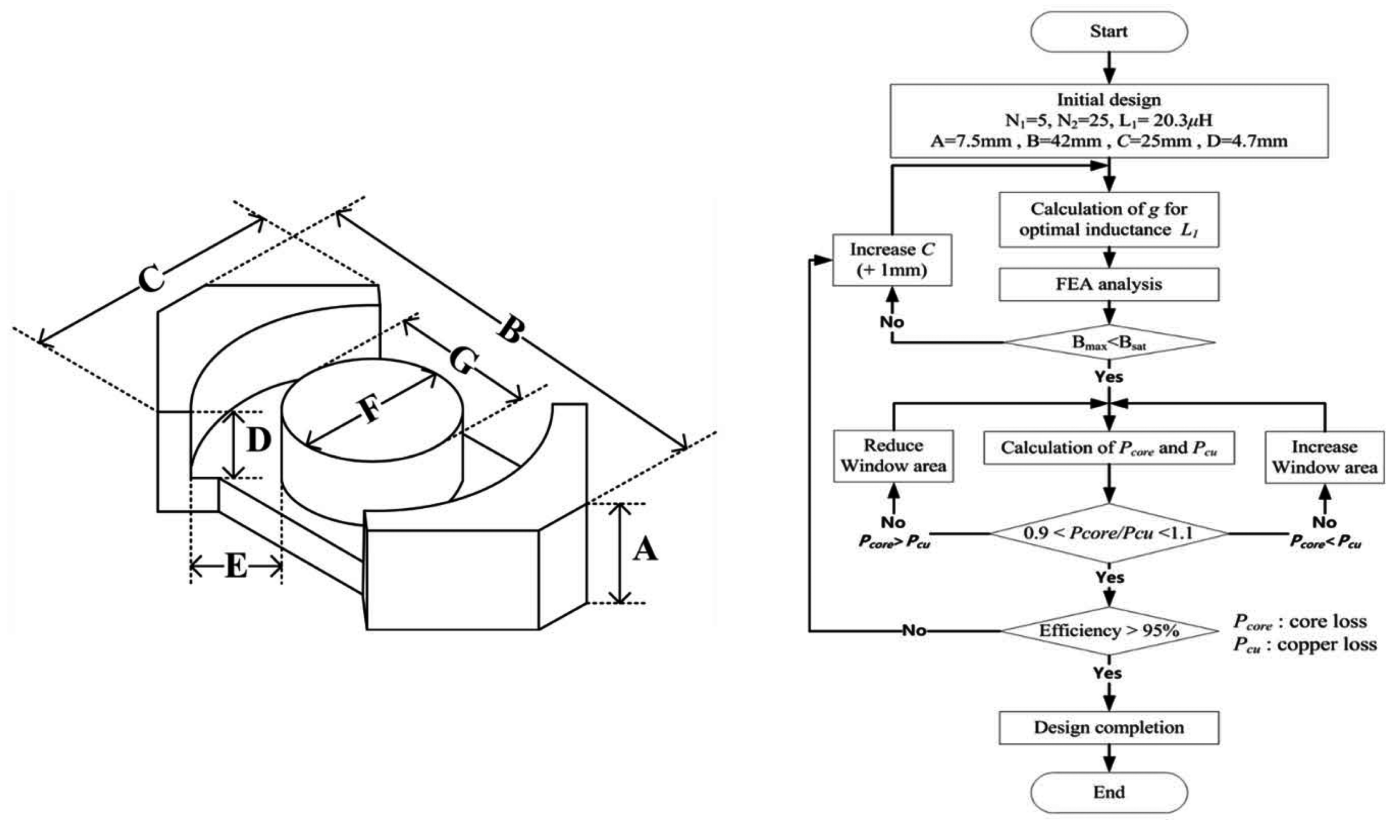

Fig. 7. Parametric 3D CAD model and the design optimization procedure.

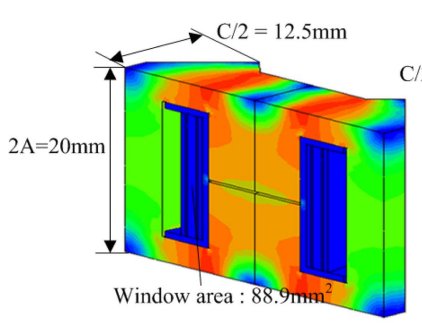

(a) Initial model

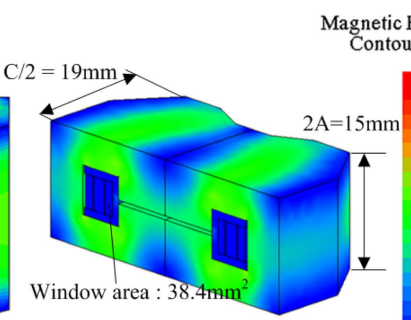

(b) Final model

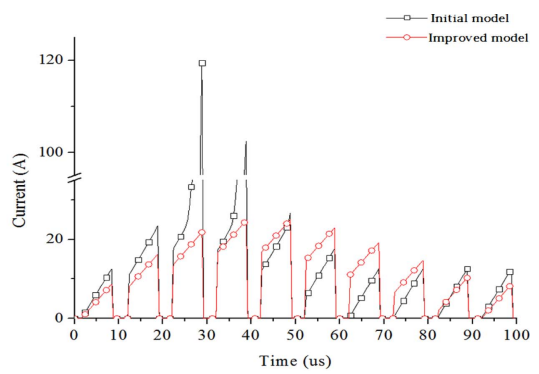

Fig. 8. (Color online) Comparison of the flux density distribution and current in the primary winding.

Table 3. Comparison of the loss analysis result.

\begin{tabular}{ccccccc}
\hline \hline Model & $\begin{array}{c}\mathrm{P}_{\text {in }} \\
{[\mathrm{W}]}\end{array}$ & $\begin{array}{c}\mathrm{P}_{\text {out }} \\
{[\mathrm{W}]}\end{array}$ & $\begin{array}{c}\mathrm{P}_{\text {core }} \\
{[\mathrm{W}]}\end{array}$ & $\begin{array}{c}\mathrm{P}_{\text {cu-1 }} \\
{[\mathrm{W}]}\end{array}$ & $\begin{array}{c}\mathrm{P}_{\text {cu-2 }} \\
{[\mathrm{W}]}\end{array}$ & $\begin{array}{c}\text { Efficiency } \\
{[\%]}\end{array}$ \\
\hline Initial & 135.2 & 120.8 & 3.08 & 6.5 & 4.6 & 89.4 \\
Final & 128.2 & 121.9 & 3.27 & 1.6 & 1.4 & 95.1 \\
\hline
\end{tabular}

\subsection{Optimization result}

Figure 8 shows the final core structure model and the flux density distribution and current in the primary winding. In this result, the local saturation point is removed, and the primary winding is not saturated in the final model. The efficiency at the rated power is improved about $6 \%$, as shown in Table 3 .

Figures 9 and 10 show the prototypes and the efficiency test result according to the output power, respectively. In the final model, the overall efficiency is improved, and the rating efficiency is largely improved by reducing the

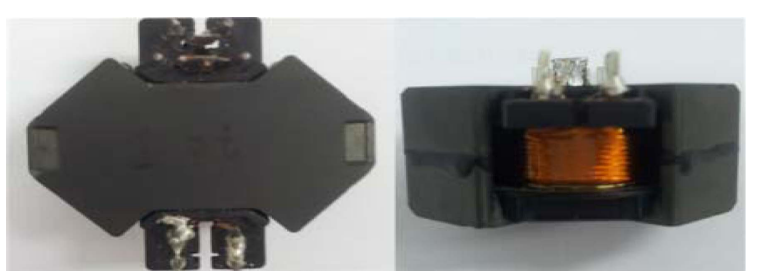

(a) Initial model

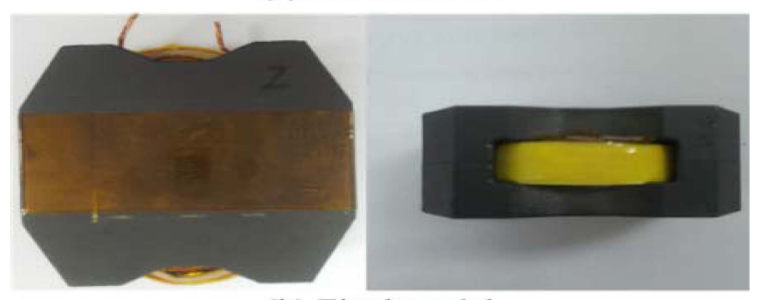

(b) Final model

Fig. 9. (Color online) Test prototypes.

copper loss. In addition, the overall volume of the core is reduced by about $13 \%$. 


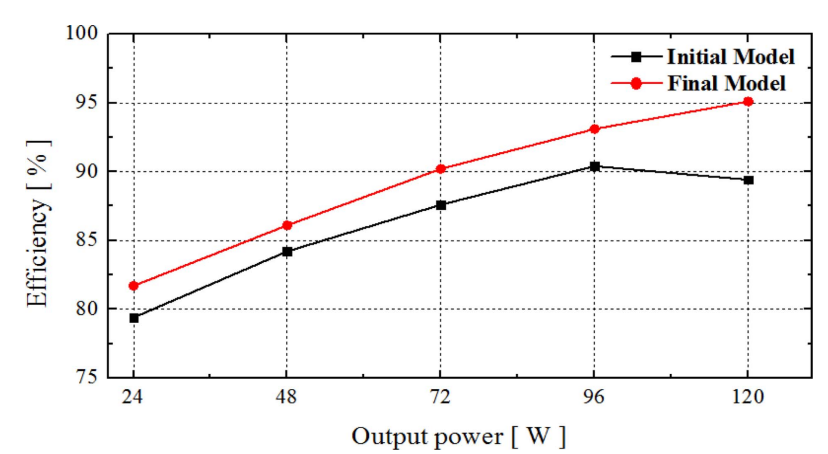

Fig. 10. (Color online) Efficiency comparison, according to the output variation.

\section{Conclusion}

This paper presents a core structure design procedure to improve the efficiency, and to reduce the size of the core. The design procedure is based on the correlation characteristics between the core and the copper loss. The optimum core structure is determined by the component ratio of losses. An analysis model is proposed, in order to obtain an analysis result of high accuracy. The operation of the converter is realized by the external circuit of the FEA, and is verified by testing the prototypes. The proposed analysis model and design procedure of the transformer can be applied to any kind of transformer, regardless of the operating frequency. Using the proposed method, the core volume is reduced by about $13 \%$, and the efficiency is improved by about $6 \%$.

\section{Acknowledgments}

This work was supported by a Kyungnam University Foundation Grant, 2013.

\section{References}

[1] W. Xiao, N. Ozog, and W. G. Dunford, IEEE Trans. Ind. Electron. 54, 3 (2007).

[2] N. Femia, G. Lisi, G. Petrone, G. Spagnuolo, and M. Vitelli, IEEE Trans. Ind. Electron. 55, 7 (2008).

[3] G. Petrone, G. Spagnuolo, and M. Vitelli, IEEE Trans. Ind. Electron. 59, 12 (2012).

[4] R. Petkov, IEEE Trans. Power Electron. 11, 1 (1996).

[5] William Gerard Hurley, Werner Hugo Wölfle, and John G. Breslin, IEEE Trans. Power Electron. 13, 4 (1998).

[6] H. R. Karampoorian, Gh. Papi, and A. Zadehgol, in Proc. IEEE Power India Conference (2006).

[7] Mika Sippola and Raimo E. Sepponen, IEEE Trans. Power Electron. 17, 5 (2002).

[8] J. Reinert, A. Brockmeyer, and R. W. De Doncker, in Proc. of 34th Annual Meeting of the IEEE Ind. Appl. Society 3 (1999).

[9] L. Jieli, T. Abdallah, and C. R. Sullivan, in Proc. 36th Annual Meeting IEEE Ind. Appl. Society 4 (2001).

[10] Alexander D. Podoltsev, Irina N. Kucheryavaya, and Boris B. Lebedev, IEEE Trans. Magn. 39, 1 (2003). 